\title{
Modelling of multimode selenide-chalcogenide glass fibre based MIR spontaneous emission sources
}

\author{
S. Sujecki ${ }^{1,2}$, Ł. Sójka ${ }^{1}$, E. Bereś-Pawlik ${ }^{1}$, R. Piramidowicz ${ }^{3}$, H. Sakr ${ }^{2}$, Z. Tang ${ }^{2}$, E. Barney ${ }^{2}$, \\ D. Furniss' ${ }^{2}$, T.M. Benson ${ }^{2}$, A.B. Seddon ${ }^{2}$
}

${ }^{1}$ Department of Telecommunications and Teleinformatics, Faculty of Electronics, Wroclaw University of Science and Technology, Wyb. Wyspiańskiego 27, 50-370 Wrocław, Poland

${ }^{2}$ George Green Institute for Electromagnetics Research, The University of Nottingham, University Park, NG7-2RD, Nottingham, UK

${ }^{3}$ Institute of Microelectronics and Optoelectronics, Warsaw University of Technology

Nowowiejska 15/19, 00-665 Warsaw, Poland

e-mail: Slawomir.Sujecki@notingham.ac.uk

\begin{abstract}
Chalcogenide glass fibres have been demonstrated as a suitable medium for the realisation of spontaneous emission sources for mid-infrared photonics applications with a particular emphasis on sensor technology. Such sources give a viable alternative to other solutions due to their potentially low cost, high reliability and robustness when pumped using commercially available semiconductor lasers. We present a comprehensive analysis of the properties of selenide-chalcogenide glass fibres applied as spontaneous emission sources. We extract the modelling parameters from measurements using in house fabricated bulk glass and fibre samples. We apply the well-established rate equations approach to determine the level populations, the distribution of the photon intensity within the fibre and the output power levels. We compare the modelling results with experiment.
\end{abstract}

Keywords: Mid-infrared photonics, chalcogenide glass fibres, numerical modelling.

\section{INTRODUCTION}

Mid-infrared (MIR) light has many applications in medicine, pharmacy, security and environment monitoring. Many kinds of sources of MIR light have been developed. These include include quantum cascade lasers (QCLs), optical parametric oscillators (OPOs), difference frequency generation (DFG) sources, solid state, fibre lasers, gas lasers, solid state lasers, Globar ${ }^{\odot}$ blackbody type and spontaneous emission fibre sources. Chalcogenide fibre based spontaneous emission fibre sources find gradually more and more applications in the sensor technology. So far dysprosium (III) and praseodymium (III) doped sulfide chalcogenide glass based sources have been used for gas and water pollutant sensing [1-3]. The chalcogenide glass based spontaneous emission sources are relatively easy to fabricate, have fairly robust structure and are potentially very reliable when pumped with laser diodes. In this contribution we explore the luminescence properties of selenidechalcogenide glass fibres doped with praseodymium, dysprosium and terbium ions for potential application as MIR spontaneous emission sources for MIR light based sensors.

\section{MODEL DESCRIPTION}

For the level configurations presented in Fig.1-3 (assuming that ${ }^{3} \mathrm{~F}_{2}$ and ${ }^{3} \mathrm{H}_{6}$ for $\mathrm{Pr}^{3+}$ shown in Fig.2 are thermally coupled) one obtains the following set of 3 algebraic equations:

$$
\left[\begin{array}{ccc}
1 & 1 & 1 \\
0 & a_{22} & a_{23} \\
a_{31} & 0 & a_{33}
\end{array}\right] *\left[\begin{array}{l}
N_{1} \\
N_{2} \\
N_{3}
\end{array}\right]=\left[\begin{array}{c}
N \\
0 \\
0
\end{array}\right]
$$

where the coefficients $\mathrm{a}_{\mathrm{n}}$ are given by the following formulae:

$$
\begin{aligned}
& a_{22}=-\left(\frac{1}{\tau_{2}}+\frac{1}{\tau_{21}^{m p}}\right) ; \quad a_{23}=\frac{\beta_{32}}{\tau_{3}}+\frac{1}{\tau_{32}^{m p}} \\
& a_{31}=\sigma_{13}^{a} \phi_{p} ; \quad a_{33}=-\left(\sigma_{31}^{e} \phi_{p}+\frac{1}{\tau_{3}}+\frac{1}{\tau_{32}^{m p}}\right)
\end{aligned}
$$

and the values of the parameters, i.e. the branching ratio for the 3-2 level transition: $\beta_{32}$, level 3 and 2 life radiative times: $\tau_{3}, \tau_{2}$, and multiphonon transition lifetimes: $\tau_{21}{ }^{m p}$ and $\tau_{32}{ }^{m p}$ are given in Tables 1-3. The values of modelling parameters have been extracted from measurements carried out on in-house prepared chalcogenide 
glass samples. The assumed dopant concentration $\mathrm{N}$ is assumed to be equal to $0.93 \times 10^{25} / \mathrm{m}^{3}$. A series of experimental studies has demonstrated that such an ion concentration can be achieved in selenide chalcogenide glass without triggering any deleterious effects [4-11]. $N_{1}, N_{2}$ and $N_{3}$ stand for the populations of levels 1,2 and 3, respectively (Fig.1, Fig.2 and Fig.3) while $\phi_{\mathrm{p}}$ is the pump photon flux. The equations (1) can be solved analytically.

\section{RESULTS}

Figure 4 shows the dependence of level populations on the pump intensity for $\mathrm{Tb}^{3+}$ doped glass. The pump wavelength is selected near the maximum of the absorption cross section, which is attained approximately at $2.95 \mu \mathrm{m}$. This figure shows that in the case of $\mathrm{Tb}^{3+}$ a complete inversion of population is possible with sufficiently large pump intensity. When wavelength is detuned from the absorption cross section maximum the curves shift to the right (Fig.5), i.e. larger pump power is required to achieve a given level of the population inversion. Nonetheless, the complete inversion of population is still possible with sufficiently high pump power. In the case of $\mathrm{Pr}^{3+}$ and $\mathrm{Dy}^{3+}$ doped glass both level 3 and level 2 participate in MIR emission (Fig.6-Fig.9). Fig.6-Fig.9 show that the selection of the pump wavelength has much more significant impact on the level of the achievable population inversion than in the case of $\mathrm{Tb}^{3+}$ doped samples. Especially, in the case of Dy ${ }^{3+}$ sample pumped at $1.8 \mu \mathrm{m}$ (Fig.9) only $0.2 \mathrm{~N}$ of all ions can be brought to level 3. In Fig. 10 we compare experimental and numerical results for the output power from a $5 \mathrm{~cm}$ long $\operatorname{Pr}^{3+}$ doped fibre with $200 \mu \mathrm{m}$ diameter, which is pumped at $1.46 \mu \mathrm{m}$. In the experiment the fibre was pumped by a fibre coupled laser diode module whilst the MIR light was collected through a monochromator, set at the centre wavelength emission of $4.7 \mu \mathrm{m}$, using a calcium fluoride lens and a germanium filter, which is used to suppress the residual pump power. When calculating the power distribution along the fibre the equations 1 have to be complemented by the ordinary differential equation describing the pump power evolution within the fibre [12]. Numerical solution was obtained using a coupled solution method [13,14,15]. The rate equations for the relevant energy levels are given in [14]. A fairly good qualitative agreement between experimental and numerical results is observed.

\section{ACKNOWLEGMENTS}

This project has received funding from the European Union's Horizon 2020 research and innovation programme under the Marie Skłodowska-Curie grant agreement No. 665778 (National Science Centre, Poland, Polonez Fellowship 2016/21/P/ST7/03666).

Table 1. Modelling parameters for $\mathrm{Tb}^{3+}$.

\begin{tabular}{|l|l|l|}
\hline Parameter & Unit & Value \\
\hline$\beta_{32}$ & & 0.088 \\
\hline$\tau_{2}$ & $\mathrm{~ms}$ & 13.1 \\
\hline$\tau_{3}$ & $\mathrm{~ms}$ & 5.9 \\
\hline$\tau_{32}{ }^{m p}$ & $\mu \mathrm{s}$ & 12 \\
\hline$\tau_{21}{ }^{m p}$ & $\mathrm{~ms}$ & 42 \\
\hline
\end{tabular}

Table 2. Modelling parameters for $\operatorname{Pr}^{3+}$.

\begin{tabular}{|l|l|l|}
\hline Parameter & Unit & Value \\
\hline$\beta_{32}$ & & 0.39 \\
\hline$\tau_{2}$ & $\mathrm{~ms}$ & 12 \\
\hline$\tau_{3}$ & $\mathrm{~ms}$ & 4 \\
\hline$\tau_{32}{ }^{m p}$ & $\mathrm{~s}$ & 1.6 \\
\hline$\tau_{21}{ }^{m p}$ & $\mathrm{~ms}$ & 70 \\
\hline
\end{tabular}

Table 3. Modelling parameters for $\mathrm{Dy}^{3+}$.

\begin{tabular}{|l|l|l|}
\hline Parameter & Unit & Value \\
\hline$\beta_{32}$ & & 0.08 \\
\hline$\tau_{2}$ & $\mathrm{~ms}$ & 6.1 \\
\hline$\tau_{3}$ & $\mathrm{~ms}$ & 2.2 \\
\hline$\tau_{32}{ }^{m p}$ & $\mathrm{~s}$ & 0.17 \\
\hline$\tau_{21}{ }^{m p}$ & $\mathrm{~s}$ & 160.0 \\
\hline
\end{tabular}

$\mathrm{Tb}^{3+}$

3

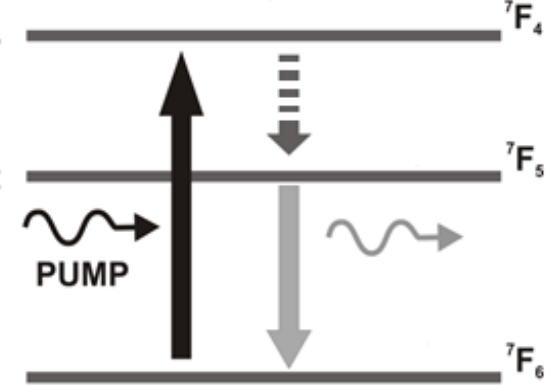

Fig.1. Schematic diagram of energy levels of $\mathrm{Tb}^{3+}$ pumped at approximately $3 \mu \mathrm{m}$.

$\mathrm{Pr}^{3+}$

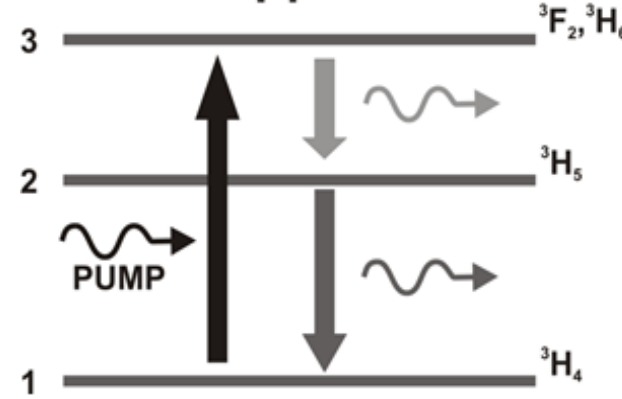

Fig.2. Schematic diagram of energy levels of $\mathrm{Pr}^{3+}$ pumped at approximately $2 \mu \mathrm{m}$. 


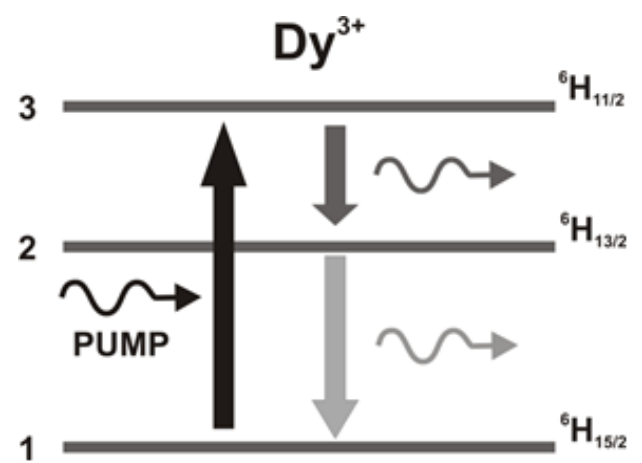

Fig.3. Schematic diagram of energy levels of $\mathrm{Dy}^{3+}$ pumped at approximately $1.7 \mu \mathrm{m}$.

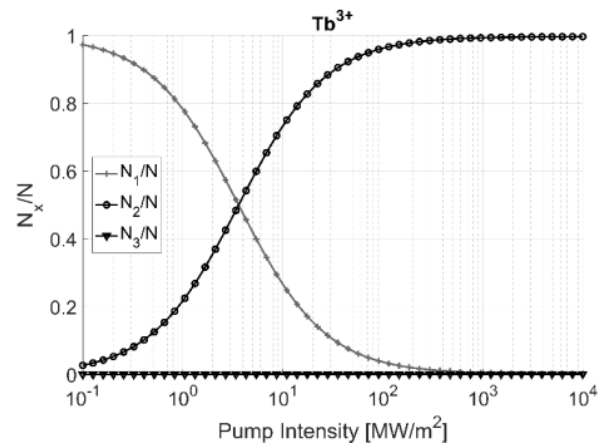

Fig.4. Dependence of level populations on the pump intensity for $\mathrm{Tb}^{3+}$ doped chalcogenide glass pumped at $3 \mu \mathrm{m}$.

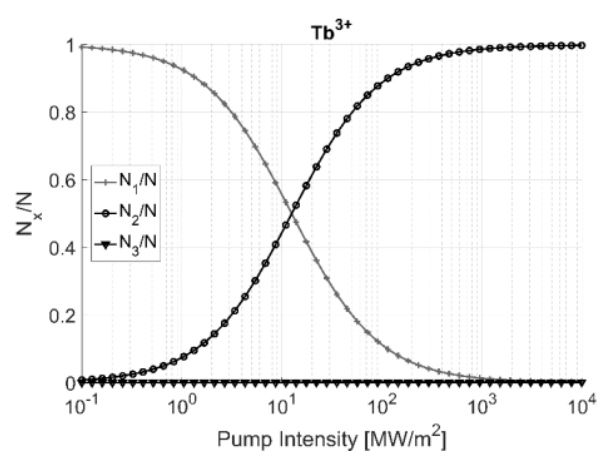

Fig.5. Dependence of level populations on the pump intensity for $\mathrm{Tb}^{3+}$ doped chalcogenide glass pumped at $2.8 \mu \mathrm{m}$.

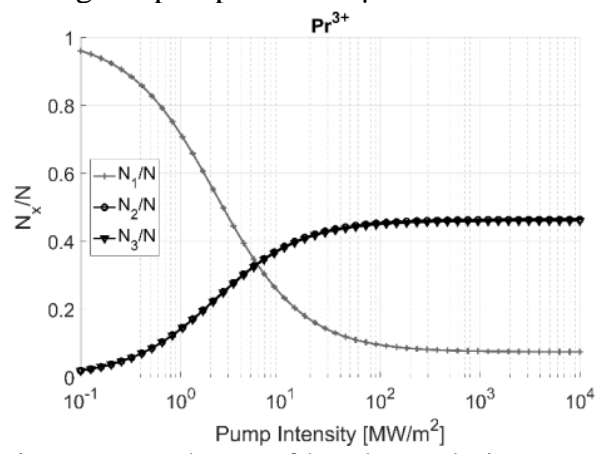

Fig.6. Dependence of level populations on the pump intensity for $\operatorname{Pr}^{3+}$ doped chalcogenide glass pumped at $2 \mu \mathrm{m}$.

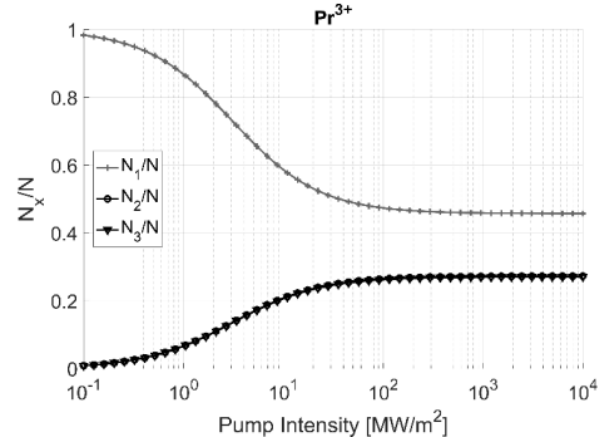

Fig.7. Dependence of level populations on the pump intensity for $\mathrm{Pr}^{3+}$ doped chalcogenide glass pumped at $2.2 \mu \mathrm{m}$.

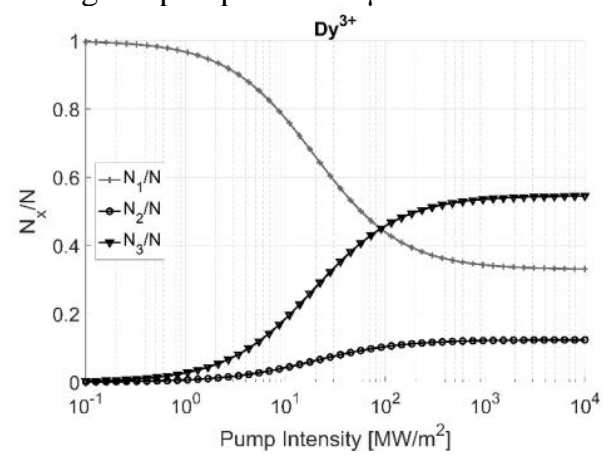

Fig.8. Dependence of level populations on the pump intensity for $\mathrm{Dy}^{3+}$ doped chalcogenide glass pumped at $1.7 \mu \mathrm{m}$.

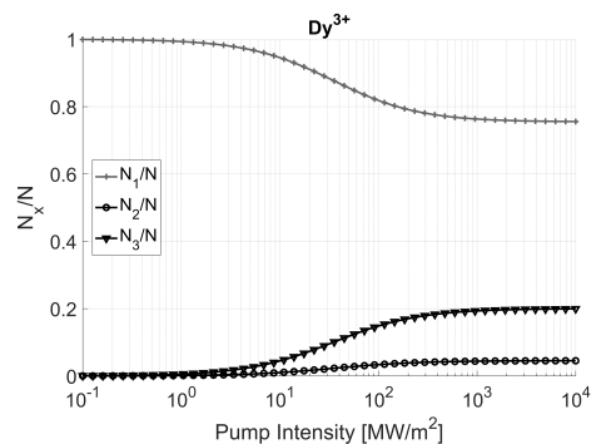

Fig.9. Dependence of level populations on the pump intensity for $\mathrm{Dy}^{3+}$ doped chalcogenide glass pumped at $1.8 \mu \mathrm{m}$.

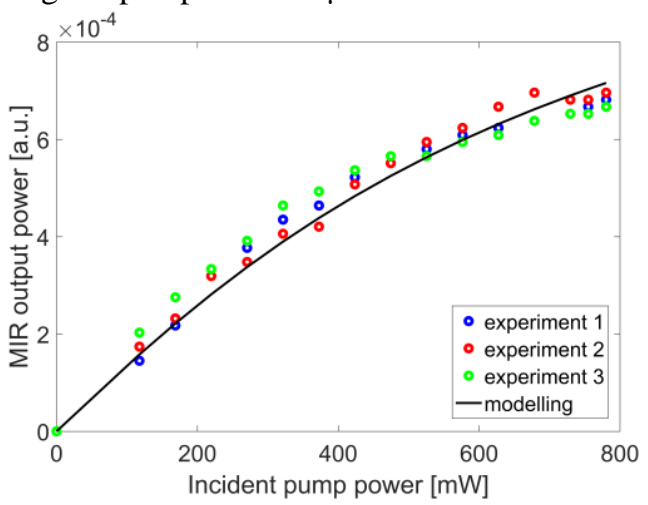

Fig.10. Dependence of MIR spontaneous emission output power on pump power for $\mathrm{Pr}^{3+}$ doped chalcogenide glass fibre pumped at $1.46 \mu \mathrm{m}$. 


\section{REFERENCES}

1. F. Charpentier, J. Troles, Q. Coulombier, L. Brilland, P. Houizot, F. Smektala, C. Boussard-Pledel, V. Nazabal, N. Thibaud, K. Le Pierres, Renversez, and B. Bureau, "CO 2 Detection Using Microstructured Chalcogenide Fibers," Sensor Letters 7, 745-749 (2009).

2. A. L. Pele, A. Braud, J. L. Doualan, R. Chahal, V. Nazabal, C. Boussard-Pledel, B. Bureau, R. Moncorge, and P. Camy, "Wavelength conversion in $\mathrm{Er}^{3+}$ doped chalcogenide fibers for optical gas sensors," Optics Express 23, 4163-4172 (2015).

3. F. Starecki, F. Charpentier, J. L. Doualan, L. Quetel, K. Michel, R. Chahal, J. Troles, B. Bureau, A. Braud, P. Camy, V. Moizan, and V. Nazabal, "Mid-IR optical sensor for $\mathrm{CO}_{2}$ detection based on fluorescence absorbance of Dy ${ }^{3+}:$ Ga5Ge20Sb10S65 fibers," Sensors and Actuators B-Chemical 207 518-525 (2015).

4. H. Sakr, D. Furniss, Z. Tang, L. Sojka, N. A. Moneim, E. Barney, S. Sujecki, T. M. Benson, and A. B. Seddon, "Superior photoluminescence (PL) of $\operatorname{Pr}^{3+}-\mathrm{In}$, compared to $\mathrm{Pr}^{3+}-\mathrm{Ga}$, selenide-chalcogenide bulk glasses and PL of optically-clad fiber," Optics Express 22, 21236-21252 (2014).

5. L. Sojka, Z. Tang, D. Furniss, H. Sakr, E. Beres-Pawlik, A. B. Seddon, T. M. Benson, and S. Sujecki, "Numerical and experimental investigation of mid-infrared laser action in resonantly pumped $\operatorname{Pr}^{3+}$ doped chalcogenide fibre," Optical and Quantum Electronics 49(2017).

6. L. Sojka, Z. Tang, D. Furniss, H. Sakr, A. Oladeji, E. Beres-Pawlik, H. Dantanarayana, E. Faber, A. B. Seddon, T. M. Benson, and S. Sujecki, "Broadband, mid-infrared emission from $\mathrm{Pr}^{3+}$ doped GeAsGaSe chalcogenide fiber, optically clad," Optical Materials 36, 1076-1082 (2014).

7. L. Sojka, Z. Tang, H. Zhu, E. Beres-Pawlik, D. Furniss, A. B. Seddon, T. M. Benson, and S. Sujecki, "Study of mid-infrared laser action in chalcogenide rare earth doped glass with $\mathrm{Dy}^{3+}, \mathrm{Pr}^{3+}$ and $\mathrm{Tb}^{3+}, "$ Optical Materials Express 2, 1632-1640 (2012).

8. Z. Tang, D. Furniss, M. Fay, H. Sakr, L. Sojka, N. Neate, N. Weston, S. Sujecki, T. M. Benson, and A. B. Seddon, "Mid-infrared photoluminescence in small-core fiber of praseodymium-ion doped selenidebased chalcogenide glass," Optical Materials Express 5, 870-886 (2015).

9. Z. Tang, N. C. Neate, D. Furniss, S. Sujecki, T. M. Benson, and A. B. Seddon, "Crystallization behavior of $\mathrm{Dy}^{3+}$-doped selenide glasses," Journal of Non-Crystalline Solids 357, 2453-2462 (2011).

10. Z. Q. Tang, D. Furniss, M. Fay, H. Sakr, L. Sojka, N. Neate, N. Weston, S. Sujecki, T. M. Benson, and A. B. Seddon, "Mid-infrared photoluminescence in small-core fiber of praseodymium-ion doped selenide-based chalcogenide glass," Optical Materials Express 5, 870-886 (2015).

11. E. R. Barney, Z. Q. Tang, A. Seddon, D. Furniss, S. Sujecki, T. Benson, N. Neate, and D. Gianolio, "The local environment of Dy ${ }^{3+}$ in selenium-rich chalcogenide glasses," RSC Advances 4, 42364-42371 (2014).

12. F. Starecki, S. Morais, R. Chahal, C. Boussard-Pledel, B. Bureau, F. Palencia, C. Lecoutre, Y. Garrabos, S. Marre, and V. Nazabal, "IR emitting Dy ${ }^{3+}$ doped chalcogenide fibers for in situ $\mathrm{CO}_{2}$ monitoring in high pressure microsystems," International Journal of Greenhouse Gas Control 55, 36-41 (2016).

13. S. Sujecki, L. Sojka, E. Beres-Pawlik, Z. Tang, D. Furniss, A. B. Seddon, and T. M. Benson, "Modelling of a simple Dy ${ }^{3+}$ doped chalcogenide glass fibre laser for mid-infrared light generation," Optical and Quantum Electronics 42, 69-79 (2010).

14. S. Sujecki, L. Sojka, E. Beres-Pawlik, R. Piramidowicz, H. Sakr, Z. Tang, E. Barney,D. Furniss, T.M. Benson, A.B. Seddon, "A study of MIR photoluminescence from $\operatorname{Pr}^{3+}$ doped chalcogenide fibers pumped at near-infrared wavelengths," submitted to SPIE Proceedings, 12th Integrated Optics Sensors, Sensing Structures and Methods Conference, Szczyrk, Poland 2017.

15. S. Sujecki, L. Sojka, E. Beres-Pawlik, H. Sakr, Z. Tang, E. Barney,D. Furniss, T.M. Benson, A.B. Seddon, "A Numerical modelling of $\mathrm{Tb}^{3+}$ doped selenide-chalcogenide multimode fibre based spontaneous emission sources," submitted to NUSOD Numerical Simulation of Optoelectronic Devices, Conference, Copenhagen, Denmark 2017. 